Profile

\title{
Brian Goldman: Twin coats, twin arts
}

Previously published at www.cmaj.ca

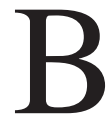

rian Goldman works both sides of the gurney. By training, he is a veteran emergency department physician at Toronto's Mount Sinai Hospital. By calling, he is host of White Coat, Black Art, the provocative CBC Radio program that places the medical profession itself under a microscope.

Since 2007, Goldman — he's been called a "radio shock doc" — has been taking an insider's look at such touchy topics as physician error, queue-jumping, burnout among medical professionals, the role of nurse practitioners and physician assistants in an overburdened system, good (and not so good) medical Samaritans and the potential health risks posed by overworked and sleep-deprived residents.

"Time was you were supposed to keep it all inside your head and your heart," says the 54-year-old Goldman. "But our culture has evolved to be more revelatory and I think most medical professionals really want to unburden themselves. The experiences they have are lonely and intense enough as it is."

The seeds of Goldman's divided professional life can be traced back to his high school days in Toronto. Despite doing "really well" in the arts

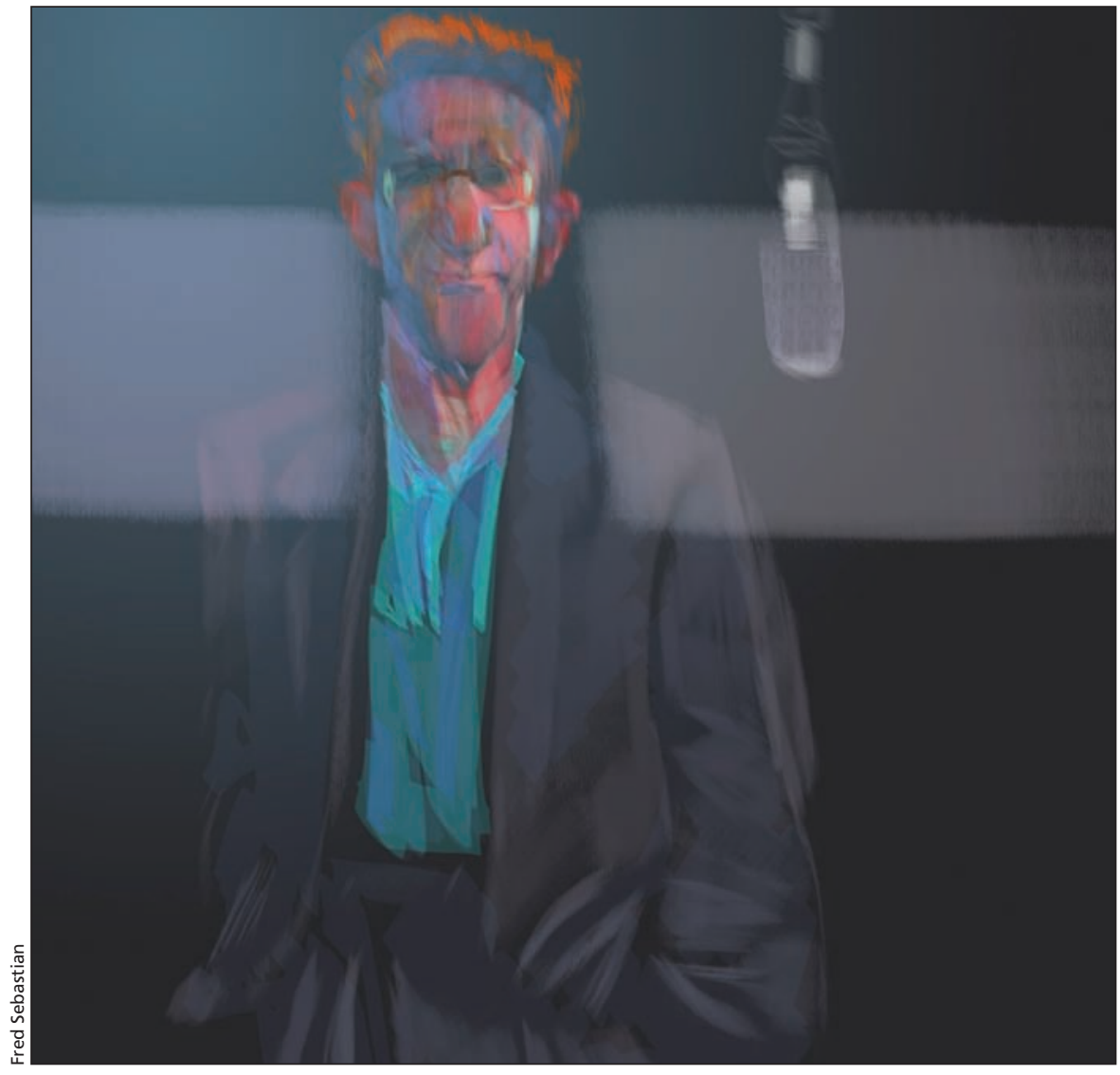

kids, you did what they did." And so he enrolled in medicine at the University of Toronto. But something didn't feel quite right.

"Even back then, my passion was clearly for writing," he says. "I just

\section{With 69 episodes of White Coat under his scrubs, Goldman's perception of his role has evolved.}

and only "acceptably well" in maths and sciences, he decided to take what he saw as the surest route to success. "The smart kids were going into professions like medicine," he says. "So if you wanted to identify with the smart didn't realize how important it was."

In the fall of 1979, Goldman's simmering ambivalence finally boiled over. He was in the midst of a twomonth elective at Johns Hopkins in Baltimore, Md., on course to becom- ing a pediatric neurologist — and unable to sleep. "The insomnia just got worse," he recalls, "except for one day. That was the day I was supposed to present rounds - do a case and a little bit of a roundup and impress my superiors - and that was the morning I finally slept in."

He took it as a sign. "It was one of those moments of stunning reversal," he says, "that in retrospect made it so clear that I was heading in the wrong direction.'

Goldman returned to Toronto in a state of mind he describes as "totally confused." Back home, he dragged himself through an unhappy internship at the Hospital for Sick Children.

Then, in desperation, he switched to internal medicine. 
More significantly, though, he took a first step toward acknowledging his unrequited passion for self-expression. He enrolled in a freelance writing course. His instructor saw some promise in him and urged him to call the Globe and Mail and pitch a story on the role of estrogen receptors in breast cancer. "I remember my hands were shaking," he says. "But the editor said, 'Great, when can you get it in?"' And with those few words, a writing career was launched.
Goldman scrawled out that first story in a longhand and got his mother to type it up. The Globe published it in 1981. He was hooked. He soon shifted to emergency medicine, working 8-10 nights a month to supplement - and complement - his growing writing habit. In 1984, he joined Mount Sinai in Toronto. He's still there, wearing the twin coats of emergency department physician and medical journalist, with a slight emphasis on the latter.

"I think I'm a storyteller who prac-

\section{A Brian Goldman sampler}

On the Canadian system. "The concept that we have of providing health care regardless of the ability to pay is a wonderful thing, and I think it would be shame to destroy it though lethargy, apathy and inertia. I think we have an ethical responsibility to do all we can to protect it."

On the fallibility of physicians. "I think we need to honour the simple fact that physicians are human, that they make mistakes like everybody else. Listen to any newscast these days, read any paper: medical errors are all around us. I think physicians are among the most ethically grounded people you will ever meet, but they have been willfully blind to the inherent lack of safety in our health care system. Decades after the airline industry came up with a similar safeguard, we're talking about surgical checklists. It's wonderful that we are, but it's decades late."

On the best use of human resources: "We don't want to have overqualified people doing everything. We have to figure out who we need to deliver care, who has the right mix of skill and experience and education. I envision a system that has much more in the way of nurse practitioners, physicians' assistants what they call in the United States mid-level medical practitioners - meeting the more basic health needs of Canadians, and then a smaller number of highly paid, highly motivated and very happy family physicians, and an even smaller number of highly qualified and even more highly paid specialists."

On the crisis in family medicine. "Right now in family medicine there is a fundamental, existential crisis. They have to sort it out and they probably have to sort it out by themselves. They can continue as they are, trying to be all things to all people, while, at the same time, there are centrifugal forces pulling them in the direction of specialization. So you've got family physicians who are only doing emergency medicine or pain management or palliative care, and family physicians who only do obstetrics or anesthesia - all of them are specialists."

On perspective and change. "I think medical professionals often lack perspective. They're so caught up in just trying to make it through the day without stepping on too many land mines that they don't have time to think more broadly. I can tell you who does have time to think more broadly: organized medicine. And organized medicine has not served physicians well for a couple of generations. Organized medicine has a nasty habit of acting like an entrenched bureaucracy, of acting as a brake on meaningful change." tises medicine," he says. "But I put a lot of effort into becoming a physician, and I was determined to make a go of it on some level, even as I explored this other part of me."

From print, Goldman soon branched into other media. He became a contributor to Sunday Morning and Ideas on CBC Radio and to The National and The Health Show on CBC Television. In October 1988, he hit the journalistic jackpot with a Sunday Morning scoop on Connaught Laboratories' purchase of untested blood products from the United States, an exercise in recklessness that ultimately led to the infection of more than 20000 Canadians with hepatitis $\mathrm{C}$ and HIV.

His favourite medium? "Oh, radio," he replies. "It allows you to tell stories that are intimate, very personal. With radio, you can be driving a car or making dinner and still be engaged."

In about 2005, Goldman came up with what he calls a "hare-brained idea" for a book. It was to be called Medical B.S. All 25 publishers he shopped it to thought it was a bad idea - "too negative," he says. But buoyed by two unexpected publishing successes with similarly scatological titles, philosopher Harry Frankfurt's scholarly On Bullshit and Laura Penny's Your Call Is Important To Us: The Truth About Bullshit, Goldman persisted.

"I felt I'd put my finger on something," he says. "So I took my book proposal and turned it into a radio proposal. The idea was to take what health professionals say in nurses' and doctors' lounges, and make those conversations public so as to give the listener the feeling they are eavesdropping. And I wanted physicians and nurses to say, 'That sounds like us, we could be having that conversation."'

White Coat, Black Art debuted in the summer of 2007 with a pull-nopunches attitude and a snappy catchphrase: "That's medicine from my side of the gurney."

Goldman quickly hit his stride that first season with a two-parter on medical error, in which several highly regarded physicians talked about their own mistakes on the job, some of which even resulted in the death of patients. "It was raw and unvarnished, 
and it was what made White Coat important," he says.

Important, perhaps, but far from universally embraced.

"Most of my colleagues are appreciative of the show, but certainly there are vested interests that think it's too revealing," he says. "Every once in a while, I'll find out that people I interviewed for a show had some difficult conversations with their bosses afterwards."

One prominent physician who has adopted a grin-and-bear-it attitude to Goldman's brand of revelatory journalism is new CMA president Jeff Turnbull.

"Having the light shone upon us is uncomfortable at times," says Turnbull. "But, as we attempt to transform the health care system, it's important we have an informed public. My sense is that anything that demystifies what we do, that makes medicine more transpar- ent and shows physicians to be human is a good thing. In that way, I think Dr. Goldman is doing a service to the medical profession.'

With 69 episodes of White Coat under his scrubs, Goldman's perception of his role has evolved.

"It's changed from being simply informing to trying to be transformative," he says. "It's amazing what I see in my travels, the little pockets of innovation, people solving problems that seem to be intractable - I see now that they aren't. There are fixes to be had."

Goldman, by his own accounting, has learned two key lessons from his professional juggling act, both bordering on the miraculous. "Personally, I have learned that there are miracles for people, satisfying changes to be had in mid-career," he says. "As for my col- leagues, the people whose stories I tell, it's just that they get up every day, and despite all the obstacles, they do what they do."

\section{David McDonald}

Filmmaker and writer

Ottawa, Ont.

White Coat, Black Art returns to $C B C$

Radio One on Saturdays at 11:00 am, beginning Sept. 11, 2010. After four successful seasons, the show has finally achieved "permanent" status at the $C B C$, meaning more episodes and a year-round on-air presence. Brian Goldman can also be heard as $C B C$ Radio One's resident "house doctor," popping up on afternoon shows across the country to discuss medical issues.

David McDonald is an Ottawa writer and filmmaker and a former CBC Radio broadcaster. 